\title{
Chapter 9 \\ Situating Fear of Crime: The Prospects for Criminological Research to Use Smartphone Applications to Gather Experience Sampling Data
}

\author{
Alexander Engström and Karl Kronkvist
}

\section{Introduction}

Because fear of crime is just a feeling, some might wonder why it is important, particularly as a target for police action. Certainly, crime itself must be more important than mere feelings about crime? (Cordner 2010, p. 1)

Although some may argue that fear of crime is "just a feeling", research indicates that its consequences may be severe, and include negative effects on individual mental health, physical functioning and perceived quality of life (Stafford et al. 2007). Worrying about becoming a victim of a crime may also restrict individuals' daily routines, with them e.g. choosing to stay at home rather than participate in public environment activities, which may in turn have negative effects on community-level crime rates due to decreased informal social control, or fewer "eyes on the street" (Wilson and Kelling 1982; Skogan 1986; Hale 1996). Given the potential negative impact of fear of crime at both the individual and community levels, in addition to the fact that fear is more prevalent in the population than victimisation per se (e.g. Hale 1996; SNCCP 2017), we believe that strategies to reduce fear of crime should be of focal concern in the field of next-generation community policing. ${ }^{1}$

Designing best practice initiatives to reduce fear of crime, however, requires state of the art knowledge on the outcome of interest. Although there is a great deal of

\footnotetext{
${ }^{1} \mathrm{~A}$ version of this paper was first presented at the Next Generation Community Policing conference held in Heraklion, Greece in October 2017.
}

\author{
A. Engström $(\bowtie) \cdot K$. Kronkvist \\ Department of Criminology, Malmö University, Malmö, Sweden \\ e-mail: alexander.engstrom@mau.se; karl.kronkvist@mau.se
}


literature focused on conceptualisations, definitions and measures of fear of crime (e.g. Ferraro and LaGrange 1987; Ferraro 1995; Farrall et al. 1997; Hough 2004), and also on explanations of fear (e.g. Box et al. 1988; Roman and Chalfin 2008), we have identified two gaps in the knowledge from existing research. First, fear of crime is predominantly studied from a cross-sectional perspective, with respondents being asked, often on a yearly basis using different population samples, to rate their average experiences of fear (e.g. Skogan and Maxfield 1981; Gibson et al. 2002; Brunton-Smith and Sturgis 2011). The widely used cross-sectional approach has restricted the opportunities for examining variations in individual-level fear of crime over time and space, despite the fact that researchers have argued that fear of crime should be studied as a dynamic rather than a static experience (Hale 1996; Pain 1997, 2000). Second, and in line with research on offending (Wikström et al. 2012), we would argue that fear of crime is dependent on individual attributes and experiences in interaction with environmental factors. Fear of crime should thus be studied using methods that capture person-setting interactions, i.e. situations in which fear of crime is experienced.

The aim of this paper is to present an overview of the situational fear of crime concept and of how the technical evolution of smartphones has provided researchers with new tools to gather data that were previously unobtainable. It will be argued that the use of situational research instruments provides knowledge on fear of crime that may be beneficial for both researchers and practitioners. A focus on situational fear of crime does not mean dismissing other approaches to studying fear of crime but is rather one of a number of perspectives that may be employed in the study of this phenomenon. We would argue, however, that previous research has directed insufficient attention at the situational dimension.

\section{Fear of Crime, Situational Dynamics, and Lifestyle-Routine Activities}

Research has provided a number of insights into why individuals experience fear of crime. For instance, fear of crime is dependent on individual attributes (such as gender and age) as well as previous experiences of criminal victimisation (see Box et al. 1988; Hale 1996; Pain 2000). Research also demonstrates that fear of crime is correlated with both physical characteristics (such as signs of decay and poor lighting) and social characteristics (such as social networks and cohesion) of the immediate environment (see Lorenc et al. 2012, 2013). Although individual and environmental characteristics are important in the explanation of fear of crime, we believe that there is a black box that still needs to be explored in order to fully understand how the individual-environment nexus generates fear of crime.

Proceeding on the basis of the Situational Action Theory of crime causation, our hypothesis is that fear of crime may be explained by reference to the same mechanisms that are used to explain both participation in crime and criminal 
victimisation; it is the interaction between "kinds of people" and "kinds of settings" that creates situations (Wikström et al. 2012) in which fear of crime may be experienced as a situational phenomenon. Pain (2000) provides an illustrative example of this conceptual approach when she argues that places are not themselves fear-inducing but rather serve to trigger individuals' internal fears that are related to other factors, for example, women's fear of men. The situation itself consists of the person(s) present, the location in which the situation is played out, and the kind of activity taking place (Pervin 1978). Although a situation involves both the individual and the environment, in the context of the situational approach, it is the interaction between a person and a particular setting within the environment that needs to be examined (Wikström et al. 2012). While researchers have begun to investigate the situational dynamics of offending and victimisation (Wikström et al. 2012; Bernasco et al. 2013; Averdijk and Bernasco 2015), less is known about the situational dynamics of fear of crime (for an exception see Solymosi et al. 2015).

Situational fear of crime must be understood within a theoretical framework that allows for situational explanations. Situational Action Theory explains individual actions (i.e. why individuals act as they do either after deliberation or habitually), and other, non-action based theories are therefore needed as a complement if we are to understand outcomes other than actions (e.g. victimisation and fear of crime). Lifestyle-Exposure Theory explains how risky lifestyles lead to some people being more exposed to environments in which victimisation is more likely to occur (Hindelang et al. 1978), while Routine Activities Theory describes what it is that makes environments criminogenic (Cohen and Felson 1979). These theories are commonly merged into a Lifestyle-Routine Activities Theory (McNeeley 2015) and are compatible as a result of their shared focus on criminal opportunities or crime incidents. Similarly, Lifestyle-Routine Activities Theory may assist in understanding why people are exposed to situations which contain known feargenerating cues ("opportunities for fear"). These fear-generating cues may, for instance, be related to Routine Activities Theory's basic explanation of the factors required for a crime to occur, once we introduce a tweak to capture the subjective fear experience; fear is more likely when a perceived suitable target coincides in time and space with a perceived motivated offender in the perceived absence of capable guardians (for the original formulation, see Cohen and Felson 1979). Further, and perhaps more importantly, Lifestyle-Routine Activities Theory may also contribute to a greater understanding of how people with different lifestyles perceive similar situational cues. It is not unlikely that a study of the fear of crime that focuses on the person-setting interaction may reveal that individuals who are highly exposed to situations that the literature defines as fear-generating are in fact less fearful as a result of their knowledge of and habituation to these kinds of situations.

Importantly, lifestyle was originally operationalised via various proxy measures, such as age and gender (e.g. Hindelang et al. 1978) which is clearly not linked to any form of situational methodology. More recent studies have employed a somewhat more refined operationalisation of lifestyle, but they still generally omit actual situational measures (e.g. Schreck et al. 2002; Svensson and Pauwels 2010). 
A situational measure of lifestyle must capture the true essence of a lifestyle as it is manifested in various situations; in the interactions between a person and the environment. When fear of crime is studied in terms of the units in which it is experienced (situations), it may be possible to unravel the mediating effect of lifestyles on the historically demonstrated connections between proxy measures and levels of fear. There is research that points in this direction (see Mesch 2000), although it has not employed a genuine situational approach.

\section{Measuring Situational Dynamics and Lifestyle-Routine Activities Using Smartphones}

To capture the essence of the person-setting interaction, one must be able to gather information not only on individuals, but also on the time, place, and content of a specific setting. In previous research on the situational dynamics of crime causation, the Space-Time Budget interview has been proposed as a viable means of retrospectively charting respondents' everyday activities in detail (for details see Wikström et al. 2012; Hoeben et al. 2014). The Space-Time Budget has however been subject to criticisms linked to problems of memory bias, concerns related to the size of the time-slots employed and the possibility of capturing uncommon events such as offending, victimisation (Hoeben et al. 2014) and thus potentially also experiences of fear of crime. Another methodological approach, which may not suffer from these potential flaws when it comes to gathering self-reported situational data, is the Experience Sampling Method (ESM) (Larson and Csikszentmihalyi 1983). ESM enables researchers to study activity patterns in individuals' everyday lives (e.g. Kahneman et al. 2004) with activities, feelings, and emotions, for example, being captured as they occur at a specific point in time and space (Larson and Csikszentmihalyi 1983). The methodology requires a signalling device to alert participants and a questionnaire that the participant fills in at the moment of the alert, which originally took the form of a personal pager and a paper questionnaire (Csikszentmihalyi and Larson 1987).

The emergence of smartphones has revolutionised the ESM procedure for a number of reasons. The smartphone releases respondents from the burden of using additional paraphernalia (e.g. pagers and paper questionnaires) since the phone itself contains these functionalities, and most individuals own a device since the smartphone has become an "integrated part of the lives of most people in Western countries" (Raento et al. 2009, p. 427). A smartphone application can notify the respondent by sending a push notification, making the person aware that it is time to answer one or more questions in a built-in, short questionnaire (see Gaggioli et al. 2013). In addition, a smartphone application can quite easily gather latent time and geo data using built-in smartphone functions. This ability to gather latent 
data is also likely to provide more accurate information on time and location than self-reported data, as well as easing the burden of participation since these data are collected automatically. Finally, smartphone applications also provide the researcher with numerous possibilities for the use of systematic procedures. For instance, notifications to respondents may be sent at random points in time, within specific time-slots (e.g. morning, mid-day, afternoon, or evening) (Solymosi et al. 2015), or when respondents enter a geo-fenced area of interest (a specific neighbourhood, a shopping area, or similar) (Chataway et al. 2017).

The ESM approach based on the use of smartphones has been successfully employed in several studies, which have, for example, examined variations in individual emotions such as happiness and stress over space and time (MacKerron and Mourato 2013; Sonck and Fernee 2013; Shoval et al. 2018). To our knowledge, however, only two published studies have examined fear of crime as a situational event using the ESM approach in combination with smartphone applications. In one pioneering ESM study, Solymosi et al. (2015) argue that fear of crime should be viewed as an event rather than an abstract long-term experience. They studied whether fear of crime varies between and within individuals both over the course of the day and between different places. The study participants were alerted at random times, up to four times each day, over a 30-day period, and were asked to answer a few short questions regarding their worries about becoming a victim of a crime at that specific moment. In addition, the application gathered relevant spatial data and the time of the report.

The other ESM study on fear of crime (Chataway et al. 2017) used a somewhat different approach. Instead of notifying respondents at random times during the day, Chataway and colleagues alerted the participants at specific places. Having first geo-fenced ten areas (e.g. shopping areas, beaches, etc.), the participants were notified as they entered these zones, which was detected by the built-in GPS sensor in their smartphones. In addition, instead of simply asking a short question on the experience of fear of crime, Chataway and colleagues employed a much larger questionnaire focused on four dimensions of fear of crime, which had been inspired by the work of Jackson (2005). Further, in addition to the study gathering auxiliary spatial and temporal data on the responses, the participants were also asked to assess their immediate environment (e.g. disorder, perceived informal social control) when they received a notification.

Although based on small numbers of participants, these studies confirm that an ESM approach to fear of crime is possible. For instance, Solymosi et al. (2015) found support for inter- and intra-individual variations in fear of crime; in fact, the participants were most often not afraid at all, but when fear was experienced, it varied in space and time and was particularly concentrated to specific geographic hotspots. However, the most important contribution of the two ESM studies to the research on fear of crime lies in the way they have challenged the current knowledge base. 


\section{Locating Fear in Place, Time and Situation: The Prospects for Future Research}

In this paper we have argued that fear of crime should be viewed and studied as a situational experience. Building on well-established criminological theory, we believe that the person-setting interaction constitutes the key element for a situational approach. By expanding our understanding of situational fear of crime we may also advance towards the next generation of fear-reducing strategies. This would involve not only focusing strategies on place and time, but also on the interactions between individuals and their environments, in which place and time may of course play an important, but not exclusive role, in the emergence of fear.

We also believe, however, that despite their major contribution as pioneering studies, the two existing studies on situational fear of crime do not fully capture situational dynamics in an entirely appropriate way. Although both studies gather relevant situational data on time and place, time and place must not be confounded with situation. Chataway et al. (2017) supplement the geographical location with additional relevant characteristics relating to the area concerned, but these variables (in addition to time) only represent some of the elements of a situation. The ESM approach in general, however, is highly relevant for studying the person-setting interaction; it offers the ability to understand the actual situational cues that are important in the person-setting interaction.

Further, a situational perspective on fear of crime needs to be based on a sound theoretical framework, as is the case with any credible explanation of any phenomenon. We have argued that conceptions drawn from Situational Action Theory and Lifestyle-Routine Activities Theory may constitute a foundation from which our hypotheses on situational fear of crime can be tested. This is not to say that other theories of fear of crime lack importance, but is rather intended to show the potential of established criminological theories in the context of this endeavour. Research instruments that use an ESM approach in combination with our suggested theoretical framework may provide insights that will help the research field move forward by addressing largely unanswered questions regarding intraand interpersonal variations in fear across space and time. The main benefit of adding an adequate theoretical foundation is that this should allow us to actually explain situational fear of crime rather than merely describing it. We believe that Situational Action Theory and Lifestyle-Routine Activities Theory may explain the mechanisms that are present prior to and during person-setting interactions, since it may explain both which persons find themselves in certain situations, and how different people perceive the same situations.

Finally, and perhaps most importantly, it is essential to emphasise the potential for the wider use of research tools that employ an ESM methodology. These tools may be relevant outside the academic sphere because they allow for the more direct measurement of situational phenomena. It is thus not surprising that the ESM approach has been proposed as a highly relevant tool for policy makers in many different areas (MacKerron and Mourato 2013). We maintain that fear of crime is 
one such area because situational research on fear of crime is highly relevant both for public agencies, such as law enforcement agencies, and private organisations that are involved in fear reduction programmes. We urge the research community to adopt a situational approach to the study of fear of crime. We would encourage the use of such an approach both to explore the technological possibilities of employing an ESM methodology, and to provide relevant theoretical explanations when fear of crime is examined. Improved understanding provides a basis for better solutions, which may in turn have practical implications for the development of safer urban communities.

\section{References}

Averdijk, M., \& Bernasco, W. (2015). Testing the situational explanation of victimization among adolescents. Journal of Research in Crime and Delinquency, 52(2), 151-180.

Bernasco, W., Ruiter, S., Bruinsma, G. J. N., Pauwels, L. J. R., \& Weerman, F. M. (2013). Situational causes of offending: A fixed-effects analysis of space-time budget data. Criminology, 51(4), 895-926.

Box, S., Hale, C., \& Andrews, G. (1988). Explaining fear of crime. British Journal of Criminology, 28(3), 340-356.

Brunton-Smith, I., \& Sturgis, P. (2011). Do neighborhoods generate fear of crime? An empirical test using the British Crime Survey. Criminology, 49(2), 331-369.

Chataway, M. L., Hart, T. C., Coomber, R., \& Bond, C. (2017). The geography of crime fear: A pilot study exploring event-based perceptions of risk using mobile technology. Applied Geography, 86, 300-307.

Cohen, L. E., \& Felson, M. (1979). Social change and crime rate trends: A routine activity approach. American Sociological Review, 44(4), 588-608.

Cordner, G. (2010). Reducing fear of crime: Strategies for police. Washington, DC: US Department of Justice/Office of Community Oriented Policing Services.

Csikszentmihalyi, M., \& Larson, R. (1987). Validity and reliability of the experience-sampling method. The Journal of Nervous and Mental Disease, 175(9), 526-536.

Farrall, S., Bannister, J., Ditton, J., \& Gilchrist, E. (1997). Questioning the measurement of the 'fear of crime': Findings from a major methodological study. British Journal of Criminology, 37(4), 658-679.

Ferraro, K. F. (1995). Fear of crime: Interpreting victimization risk. Albany: State University of New York Press.

Ferraro, K. F., \& LaGrange, R. (1987). The measurement of fear of crime. Sociological Inquiry, 57(1), 70-97.

Gaggioli, A., Pioggia, G., Tartarisco, G., Baldus, G., Corda, D., Cipresso, P., \& Riva, G. (2013). A mobile data collection platform for mental health research. Personal and Ubiquitous Computing, 17(2), 241-251.

Gibson, C. L., Zhao, J., Lovrich, N. P., \& Gaffney, M. J. (2002). Social integration, individual perceptions of collective efficacy, and fear of crime in three cities. Justice Quarterly, 19(3), 537-564.

Hale, C. (1996). Fear of crime: A review of the literature. International Review of Victimology, 4, 79-150.

Hindelang, M. J., Gottfredson, M. R., \& Garofalo, J. (1978). Victims of personal crime: An empirical foundation for a theory of personal victimization. Cambridge, MA: Ballinger. 
Hoeben, M., Bernasco, W., Weerman, F. M., Pauwels, L., \& van Halem, S. (2014). The space-time budget method in criminological research. Crime Science, 3(12), 1-15.

Hough, M. (2004). Worry about crime: Mental events or mental states? International Journal of Social Research Methodology, 7(2), 173-176.

Jackson, J. (2005). Validating new measures of the fear of crime. International Journal of Social Research Methodology, 8(4), 297-315.

Kahneman, D., Krueger, A. B., Schkade, D. A., Schwarz, N., \& Stone, A. A. (2004). A survey method for characterizing daily life experience: The day reconstruction method. Science, 306(5702), 1776-1780.

Larson, R., \& Csikszentmihalyi, M. (1983). The experience sampling method. New Directions for Methodology of Social \& Behavioral Science, 15, 41-56.

Lorenc, T., Clayton, S., Neary, D., Whitehead, M., Petticrew, M., Thomson, H., Cummins, S., Sowden, A., \& Renton, A. (2012). Crime, fear of crime, environment, and mental health and wellbeing: Mapping review of theories and causal pathways. Health \& Place, 18(4), 757-765.

Lorenc, T., Petticrew, M., Whitehead, M., Neary, D., Clayton, S., Wright, K., Thomson, H., Cummins, S., Sowden, A., \& Renton, A. (2013). Fear of crime and the environment: Systematic review of UK qualitative evidence. BMC Public Health, 13(1), 496-503.

MacKerron, G., \& Mourato, S. (2013). Happiness is greater in natural environments. Global Environmental Change, 23(5), 992-1000.

McNeeley, S. (2015). Lifestyle-routine activities and crime events. Journal of Contemporary Criminal Justice, 31(1), 30-52.

Mesch, G. S. (2000). Perceptions of risk, lifestyle activities, and fear of crime. Deviant Behavior, 21(1), 47-62.

Pain, R. H. (1997). 'Old age' and ageism in urban research: The case of fear of crime. International Journal of Urban and Regional Research, 21(1), 117-128.

Pain, R. H. (2000). Place, social relations and the fear of crime: A review. Progress in Human Geography, 24(3), 365-387.

Pervin, L. A. (1978). Definitions, measurements, and classifications of stimuli, situations, and environments. Human Ecology, 6(1), 71-105.

Raento, M., Oulasvirta, A., \& Eagle, N. (2009). Smartphones: An emerging tool for social scientists. Sociological Methods \& Research, 37(3), 426-454.

Roman, C. G., \& Chalfin, A. (2008). Fear of walking outdoors: A multilevel ecologic analysis of crime and disorder. American Journal of Preventive Medicine, 34(4), 306-312.

Schreck, C. J., Wright, R. A., \& Miller, J. M. (2002). A study of individual and situational antecedents of violent victimization. Justice Quarterly, 19(1), 159-180.

Shoval, N., Schvimer, Y., \& Tamir, M. (2018). Tracking technologies and urban analysis: Adding the emotional dimension. Cities, 72, 34-42.

Skogan, W. G. (1986). The fear of crime and its behavioral implications. In E. A. Fattah (Ed.), From crime policy to victim policy. Reorienting the justice system (pp. 167-188). London: Macmillan Press.

Skogan, W., \& Maxfield, M. (1981). Coping with crime: Individual and neighborhood reactions. Beverly Hills: Sage Publications.

Solymosi, R., Bowers, K., \& Fujiyama, T. (2015). Mapping fear of crime as a context-dependent everyday experience that varies in space and time. Legal and Criminological Psychology, 20(2), 193-211.

Sonck, N., \& Fernee, H. (2013). Using smartphones in survey research: A multifunctional tool. Implementation of a time use app; a feasability study. The Hague: The Netherlands Institute for Social Research (SCP).

Stafford, M., Chandola, T., \& Marmot, M. (2007). Association between fear of crime and mental health and physical functioning. American Journal of Public Health, 97(11), 2076-2081.

Svensson, R., \& Pauwels, L. (2010). Is a risky lifestyle always "risky"? The interaction between individual propensity and lifestyle risk in adolescent offending: A test in two urban samples. Crime \& Delinquency, 56(4), 608-626. 
Swedish National Council for Crime Prevention [SNCCP]. (2017). Swedish Crime Survey 2016. English summary of Brå-report 2017:1. Stockholm: The Swedish National Council for Crime Prevention.

Wikström, P. O. H., Oberwittler, D., Treiber, K., \& Hardie, B. (2012). Breaking rules: The social and situational dynamics of young people's urban crime. Oxford: Oxford University Press.

Wilson, J. Q., \& Kelling, G. L. (1982, March). The police and neighborhood safety: Broken windows. Atlantic Monthly, pp. 29-38.

Open Access This chapter is licensed under the terms of the Creative Commons Attribution 4.0 International License (http://creativecommons.org/licenses/by/4.0/), which permits use, sharing, adaptation, distribution and reproduction in any medium or format, as long as you give appropriate credit to the original author(s) and the source, provide a link to the Creative Commons license and indicate if changes were made.

The images or other third party material in this chapter are included in the chapter's Creative Commons license, unless indicated otherwise in a credit line to the material. If material is not included in the chapter's Creative Commons license and your intended use is not permitted by statutory regulation or exceeds the permitted use, you will need to obtain permission directly from the copyright holder. 